século XIX e início do século passado, ou na busca de saúde e prazer infinitos contemporâneos. Esses contrapontos da 'natureza' dos corpos, como mostra a autora, são historicizados, mesmo que as temporalidades sejam efêmeras por não ter uma datação precisa ou presa no calendário de determinada cultura. Desconstruir as formas discursivas, como faz Denise Sant'Anna, é evitar o perigo de transformar o corpo em lugar dos universais.

1 Lucila Scavone traz essa discussão do primeiro momento do movimento feminista, baseado na noção de diferença e criando uma idéia de liberdade e autonomia das mulheres, associada a uma concepçao de conhecimento e reapropriação do próprio corpo. SCAVONE, Lucila. "Anticonceptión, aborto y tecnologías conceptivas: entre la salud, la ética y los derechos". In: SCAVONE, Lucila (Org.). Género y salud reproductiva en América Larina. Cartago: Libro Universitario Regional, 1999. p. 25-31.

${ }^{2}$ FOUCAULT, Michel. A arquelogia do saber. 3. ed. Rio de Janeiro: Forense-Universitária, 1987.

ANA MARIA MARQUES

Universidade do Vale do Itajaí

\title{
A construção da 'natureza feminina' no discurso médico
}

\author{
Uma ciência da diferença: sexo \\ e gênero na medicina da \\ mulher.
}

\section{ROHDEN, Fabíola.}

Rio de Janeiro: Editora FIOCRUZ, 2001, $223 \mathrm{p}$.

Produto de uma tese de doutorado em Antropologia Social, o livro de Fabíola Rohden analisa a temática da diferença sexual nos escritos médicos do século XIX e início do século XX, a partir das representações, das imagens que estão na base da criação da medicina da mulher. Inicialmente, diz a autora, a investigação visava a produzir uma história sobre a sexualidade e a reprodução. O exame da documentação, entretanto, revelou que, "em boa parte do século XIX especialmente, a medicina da sexualidade e reprodução era a medicina sobre a mulher, expressa sobretudo na criação de uma especialidade, a ginecologia, que se definia como 'a ciência da mulher'” (p.31).

Rohden persegue os caminhos tortuosos da construção de uma determinada concepção de diferença sexual entre homens e mulheres, demonstrando o empenho de médicos e cientistas europeus da época em estabelecer claras diferenças de caráter biológico e predeterminado entre os sexos. Essas diferenças não seriam apenas físicas, mas eram também psicológicas e morais. No discurso médico do século XIX, o sexo era entendido como um elemento natural e biológico, responsável pelo 'destino' social de homens como provedores e de mulheres como esposas e mães. Apesar dessa crença de que o sexo determinaria o destino, Rodhen chama a atenção para o que entende ser um paradoxo presente nos textos médicos: a diferença sexual era vista como natural e, ao mesmo tempo, como sendo 'instável' e 'perigosa'. Conseqüentemente, seria necessário monitorar o processo de diferenciação sexual de homens e mulheres, em particular no início da puberdade, fase na qual "as influências do meio poderiam prejudicar ou impedir que se chegasse ao resultado esperado, de amadurecimento sexual e reprodutivo de homens e mulheres" (p. 204).

Valendo-se da bibliografia existente sobre o assunto, transita por várias problematizações sobre a questão da diferença biológica e discussões teóricas elaboradas por autores/as como Thomas Laqueur, Londa Schiebinger, Michel Foucault, Ornella Moscucci, Cynthia E. Russet, Jill L. Matus, entre outros. No diálogo estabelecido com Laqueur, recupera a discussão sobre os dois modelos de interpretação do corpo feminino em relação ao masculino. O primeiro, herdado dos gregos, que admitia apenas uma estrutura básica do corpo humano, a do macho, teria prevalecido 
até o Renascimento. Essa concepção de onesex model teria sido substituída pela idéia de dois sexos, ou da diferença biológica, por volta do final do século XVIII e começo do XIX. Laqueur informa que essa mudança não foi decorrente de avanços científicos, mas das necessidades ideológicas colocadas pela nova ordem social e pelas modificações nas relações de gênero. Rodhen incorpora à sua análise as discussões sobre a leitura e releitura do corpo no período, mostrando que as correntes médicas predominantes na Europa sobre a reinterpretação biológica do corpo feminino serviram como fontes de inspiração das teorias médicas que circulavam no Brasil nos séculos XIX e XX. Discorda, todavia, da leitura sobre a diferença sexual como sendo estática e dada a priori (p.203). Afirma que "o autor não foi suficientemente sensível a certos aspectos fundamentais que revelam não apenas a 'convivência' de dois modelos, mas a natureza instável e perigosa da concepção de diferença entre os sexos elaborada pelos médicos do século XIX" (p. 20).

Já em Foucault, Rodhen inspira-se na concepção "da sexualidade como uma construção cultural e um processo complexo e instável, em que está em jogo uma multiplicidade de elementos discursivos" (p. 205-206) Sua tese aproxima-se do trabalho de Jill Matus, no que diz respeito a sexo e reprodução na medicina. Matus concebe a diferença sexual como 'instável' e 'precária', logo, sujeita às influências sociais, como por exemplo a educação feminina ou o exercício de uma atividade profissional. Essa hipótese também aparece nas teses médicas elaboradas na Faculdade de Medicina do Rio de Janeiro, no século XIX e início do XX, nas quais se baseia a pesquisa de Fabíola Rodhen. A medicina da mulher, no Brasil, propõe o estudo e tratamento das doenças, "mas como uma ciência da feminilidade, da diferença sexual e das desordens sociais relacionadas com as ameaças à delimitação dessa diferença" (p. 95).

\section{A concepção de 'diferença biológica' intensifica-se no século XIX}

A relação entre a condição biológica e os papéis sociais atribuídos aos gêneros masculino e feminino, a visão do corpo masculino como superior em relação ao feminino e a maternidade como função essencial do sexo feminino não eram idéias novas; já se faziam presentes desde o século anterior, nas reflexões de Diderot, D'Alembert, Roussel, Cabanis. No século XIX, médicos e cientistas alimentaram esse debate baseados nas descobertas 'científicas' da nova biologia, fornecendo cada vez mais elementos para provar e reafirmar o estatuto biológico e previamente dado aos sexos. Acreditavam que a sexualidade feminina estava intimamente ligada à função reprodutiva.

A segunda metade do século XIX presencia um conjunto de mudanças socioeconômicas, políticas e culturais, além de um intenso desenvolvimento tecnológico. No plano científico, as mudanças proliferam, verificando-se a construção do método anatomoclínico, a transformação dos hospitais, a classificação das doenças, as descobertas de uma série de instrumentos, procedimentos e medicamentos, como os Raios X, o estetoscópio, as vacinas e o clorofórmio. Laennec inova, introduzindo a auscultação no diagnóstico e "inventa o estetoscópio por pudor, por não ousar colocar sua orelha no peito de uma jovem moça" (p. 21). A palavra 'infecção' começa a ser usada para explicar inúmeras doenças e a 'assepsia' alarga o campo da cirurgia. O debate em torno do darwinismo e da hereditariedade "propiciará o nascimento de uma corrente de pensamento marcada pelo fatalismo genético e que culminará no eugenismo" (p. 23).

Para além dessas transformações, também se verificam no período mudanças no mercado de trabalho, no estilo de vida, bem como a propagação de um ideário feminista. A necessidade de sobrevivência levou as mulheres pobres a buscar as fábricas ou os trabalhos de baixa remuneração. Aquelas pertencentes às classes média ou alta forçavam a participação na vida pública (p. 25). Todas essas modificações despertaram o questionamento a respeito do lugar a ser ocupado pelas mulheres na sociedade, do papel dos gêneros, das diferenças entre os sexos, além do estabelecimento de regras morais para o controle do comportamento social. Qualquer tentativa de rompimento do elo mulher-reprodução representava uma ameaça, não apenas ao organismo feminino, como também à sociedade. As mulheres que lutavam por direitos ou que pretendessem ingressar em uma profissão "masculina", como a medicina, por exemplo, eram vistas como uma ameaça à ordem burguesa, sendo retratadas pelo discurso médico como "espécies híbridas", "degeneradas", "vampiras" ou mesmo 
"assassinas". Esses 'desvios' deveriam ser submetidos a uma nova forma de normatização, apoiada na perspectiva biológica de uma clara distinção entre os sexos.

\section{O surgimento da 'ciência da mulher' ou da ginecologia}

A partir do século XIX, a medicina propõe uma releitura do corpo feminino, momento em que se dá o surgimento da chamada 'ciência da mulher', descrita como uma especialidade médica cuja origem se encontra no "terreno do interesse pela diferença" (p. 35). Segundo Rodhen, toda a produção sobre o corpo, sexualidade e reprodução na mulher partia das diferenças fundamentais entre homens e mulheres, e, nesse sentido, a medicina e, mais precisamente, as especialidades voltadas à mulher e à reprodução convertem-se em uma verdadeira 'ciência da diferença', na qual se podia antever um projeto de medicalização do corpo feminino. Os médicos teriam explicado a inferioridade física, psicológica e intelectual da mulher em relação ao homem como uma realidade inscrita no próprio corpo, lócus onde natureza e destino se confundiam. Fenômenos como puberdade, gravidez e menopausa afetariam a mulher de uma maneira sem equivalentes para o homem. "É com base nessa visão biológica que se estabelecem os papéis sociais" (p. 38). As características anatômicas das mulheres as destinariam à maternidade e não ao exercício de funções públicas. A recusa da maternidade, vista como a verdadeira essência da mulher, ou da vida doméstica, era um indício de forte ameaça aos padróes e valores estabelecidos para o sexo feminino. $E$, nesse sentido, os médicos construíram papéis de gênero, apoiando-se na diferença sexual, tendo firmes propósitos de extrapolar o simples cuidado das doenças femininas, abarcando assim vários aspectos da vida social e das relações de gênero. Obviamente, não havia uma única perspectiva dentro da medicina. Até os anos de 1870 , as mulheres que praticassem crimes como o aborto ou infanticídio, ou fossem acometidas de males como a loucura, "eram consideradas mais como vítimas da falta de tutela do que responsáveis pelos seus atos". No último quartel do século XIX, pode-se verificar uma inflexão no discurso médico, que passa a "enfatizar a periculosidade natural do sexo feminino", em consonância com o modelo da degeneração em voga (p. 70).
A medicina da mulher não encontra correspondente para o sexo masculino. O homem será alvo de preocupações em função da sífilis e de outras doenças venéreas, que eram então associadas à degeneração. No caso do gênero feminino, sua natureza era concebida como potencialmente patológica, propensa a perturbações e desordens: a ginecologia, escreve Rodhen, é a especialidade que se constitui sobre essa lógica. Ademais, o surgimento da ginecologia deve ser entendido dentro do contexto do século XIX, assolado pelos graves problemas ligados à miséria, às doenças mentais, aos 'vícios', que também represen-tariam fortes ameaças ao futuro da humanidade, daí serem merecedores da atenção médica.

Muitas das teorias elaboradas pelos médicos desse período se basearam na idéia de fragilidade da natureza humana, a exemplo da teoria da hereditariedade, que desembocou em uma visão de impossibilidade de igualdade social e política e nos movimentos eugênicos. "Com base nessa concepção elabora-se um esquema no qual o homem branco, civilizado, europeu representaria a maturidade evolutiva em contraste com a mulher, o negro, o primitivo, o não europeu" (p. 27). Além disso, a natureza era entendida pelos cientistas da época como eminentemente hierárquica. No que tange à divisão da sociedade em classes, esta deveria ser valorizada para o bem do progresso social.

\section{A concepção de 'diferença biológica' nas teses médicas produzidas no Rio de Janeiro}

Na parte final do livro, para interpretar a questão da diferença sexual no Brasil, a autora analisa um conjunto de teses produzidas na Faculdade de Medicina do Rio de Janeiro, nas últimas décadas do século XIX e início do século XX. A produção médica mostra que "a medicina expressa uma preocupação singular com a delimitação do papel social da mulher, baseada na valorização da maternidade" (p. 95). Nesse sentido, a sexualidade feminina constituiu-se em um dos focos principais da atenção médica no período estudado.

Um outro aspecto que mereceu atenção especial dos médicos ginecologistas foi a relação entre órgãos genitais, sexualidade feminina e doença mental e seus respectivos tratamentos. A ênfase incidia, principalmente, sobre temas como puberdade, menstruação, loucura, onanismo, ninfomania, neurastenia, prostituição, desejo, 
menopausa, histeria, casamento, amor, entre outros. As conseqüências dessa identificação dos órgãos genitais com a sexualidade feminina e doenças mentais podem ser vistas nos argumentos médicos sobre a puberdade, fase que marcaria o nascimento da diferença, para ficarmos em um único exemplo, entre os vários arrolados no estudo. Sendo o período da puberdade muito propício ao aparecimento de doenças, como a clorose, a histeria, a loucura, a ninfomania, essa fase precisaria de cuidados muito especiais. Desse modo, exigia-se a moderação de certas atividades caracterizadas por dispêndio de energia intelectual. Sem muitos rodeios, mostrava-se que o "colégio, pelo convívio que oferece e pela exigência intelectual, deve ser preterido em prol da instrução fornecida pela própria mãe da menina" (p.28). A leitura de romances e novelas e espetáculos que prestigiassem as paixões também deveriam ser evitados. Esse enfoque se repete em outras teses analisadas pela autora.

No discurso médico 'oficial', as perturbações femininas consideradas prejudi-ciais ao bem público poderiam ser tratadas com a reclusão da mulher em asilos apropriados, sob os cuidados médicos. Uma das principais doenças que afetavam as mulheres, de acordo com os médicos brasileiros, era a histeria. A cura para esse mal seria o casamento.

Nas últimas décadas do século XIX, teria ocorrido uma valorização da mulher no que tange à reprodução, que se "torna-se especialmente importante, como uma reserva moral da sociedade, na medida em que está mais próxima da religião, do amor, da abnegação e da dedicação aos outros" (p. 123).

Algumas teses mostraram que 0 'sistema nervoso' feminino representou a base para a formulação da natureza feminina, e os papéis sociais vinculavam-se sempre às teorias biológicas vigentes à época. Em tese datada de 1840 , Firmino Junior diz que "as mulheres são mais sensíveis, mais impressionáveis, extremosas, em tudo, dadas as coisas de pouca ou nenhuma consideração, mais eloqüentes, mais sujeitas a serem vencidas, graciosas em todos os seus atos; finalmente, é no sistema nervoso que reside toda a vida da mulher" (p. 109).

Rodhen afirma que, na maior parte das teses analisadas, a "linha geral da argumentação é traçada sobre uma quase redução das funções da mulher à maternidade e ao lar e sobre uma ênfase nos perigos representados pelas tentativas de rompimento dessa equação" (p. 149).

\section{Um caso concreto: Abel Parente}

No capítulo que trata de um caso concreto de esterilização de mulheres para fins contraceptivos, envolvendo o médico italiano Abel Parente, radicado no Brasil, onde residiu por 35 anos, Rodhen traz à tona as concepções sobre a diferença sexual como aparecem nas falas dos profissionais que reagiram publicamente à questão. O método de esterilização do doutor Abel Parente despertou uma ruidosa controvérsia no meio médico brasileiro, em 1893, ano em que publicou na imprensa do Rio de Janeiro anúncios para divulgar o seu novo invento. A polêmica surgida envolveu médicos, juristas, a Sociedade de Higiene do Brasil e a Academia Nacional de Medicina. O setor dividiu-se entre prós e contras. No debate travado sobre os procedimentos do esterilizador, a autora recorta, com muita precisão, os argumentos que refletem "a íntima ligação entre os pressupostos morais e as concepções científicas acionadas" (p.156). Dessa maneira, estabelece uma ligação entre as concepções sobre a diferença discutidas no livro e como estas se materializaram nas polêmicas em torno de um caso concreto.

Para concluir, gostaria de assinalar que 0 livro de Fabíola Rodhen nos mostra como as mulheres foram percebidas pelos médicos do século XIX e início do XX - ora 'normais', ora 'prostitutas' -, apontando como se deu a criação dos infindáveis estereótipos em torno do gênero feminino. É fundamental apreendermos os caminhos de construção masculina das identidades das mulheres: frágeis, loucas, perigosas, degeneradas, prostitutas ou fatais. Essas crenças atribuíram legitimidade à pratica e ao discurso médico do século XIX. Em uma linguagem clara, Fabíola Rodhen demonstra que, no Brasil, como em outros contextos sociais europeus, no século XIX e início do século XX, as teorias médicas fundamen-taram as interpretações relativas à diferença sexual, não como uma diferença imutável e estática, mas 'instável' e ameaçadora.

ELISABETH JULISKA RAGO Pontifícia Universidade Católica de São Paulo 